\title{
Control Type
}

National Cancer Institute

\section{Source}

National Cancer Institute. Control Type. NCI Thesaurus. Code C49647.

A characteristic of a treatment regimen employed as a comparator against which the study treatment is evaluated. 